\title{
Anti-cyclic citrullinated peptide antibodies are not frequently observed in children with type 1 diabetes mellitus: a single- center study
}

\author{
Melek Yıldız', Figen İşleten², Korcan Demir ${ }^{1}$, Nilüfer Çelik², Hüseyin Anıl Korkmaz${ }^{1}$, \\ Birsen Tuğlu², Özlem Nalbantoğlu ${ }^{1}$, Behzat Özkan ${ }^{1}$ \\ Divisions of ${ }^{1}$ Pediatric Endocrinology and ${ }^{2}$ Biochemistry, Dr. Behçet Uz Children's Hospital, Izmir, Turkey. \\ E-mail: korcandemir@gmail.com \\ Received: 13th April 2016, Accepted: 7th November 2016
}

\begin{abstract}
SUMMARY: Yıldız M, İşleten F, Demir K, Çelik N, Korkmaz HA, Tuğlu B, Nalbantoğlu Ö, Özkan B. Anti-cyclic citrullinated peptide antibodies are not frequently observed in children with type 1 diabetes mellitus: A single-center study. Turk J Pediatr 2016; 58: 395-399.

Type 1 diabetes mellitus (DM) and rheumatoid arthritis (RA) have been reported to occur concurrently in some cases. This study aimed to evaluate the presence of anti-cyclic citrullinated peptide (CCP) antibodies, which have been reported to have diagnostic value for RA, in children with type $1 \mathrm{DM}$. The study included 90 children with type $1 \mathrm{DM}$ (Group 1) and 76 control cases (Group 2). The rates of reported family histories of RA and rheumatoid factor positivity did not differ between groups. In group 1 , one case $(1.1 \%)$ was positive for anti-CCP antibodies, whereas none of the controls were positive. The anti-CCP positive patient had no relevant joint complaints. Anti-CCP antibodies were rarely found in cases of pediatric type $1 \mathrm{DM}$. Thus, relevant screening in the follow-up of pediatric patients does not appear to be rational in the absence of any signs or symptoms of arthritis. The single case exhibiting a high anti-CCP level needs to be followed up for RA, although this positive result might be nonspecific and transient.
\end{abstract}

Key words: anti-cyclic citrullinated peptide antibodies, type 1 diabetes mellitus, rheumatoid arthritis.

Type 1 diabetes mellitus (DM) is a chronic disease that results from the autoimmune destruction of pancreatic beta cells by $\mathrm{T}$ lymphocytes ${ }^{1}$. Autoimmune diseases such as autoimmune thyroid disease, celiac disease, autoimmune gastritis, and Addison's disease are generally known to occur concurrently with type $1 \mathrm{DM}^{2}$. In addition, sporadic and familial concurrences of rheumatoid arthritis (RA) and type 1 DM have been reported ${ }^{3,4}$. Genetic susceptibility to both diseases has been attributed to the protein tyrosine phosphatase N22 gene (PTPN22) 620W allele, which has been associated with multiple autoimmune phenotypes ${ }^{5,6}$.

Rheumatoid arthritis (RA) is characterized by chronic inflammation of the synovial joints, leading to progressive joint erosion and, consequently, disability. Therefore, diagnosis before the occurrence of joint damage is important. To this end, anti-cyclic citrullinated peptide (anti-CCP) antibodies comprise a new group of autoantibodies reported to be of diagnostic and predictive value for RA. Despite exhibiting a similar level of sensitivity, the specificity of anti-CCP for distinguishing between RA and other rheumatic diseases is superior to that of rheumatoid factor (RF) ${ }^{7}$. Adult studies of the association between type $1 \mathrm{DM}$ and anti-CCP-detected RA have been inconclusive ${ }^{8,9}$. Furthermore, few published studies evaluated anti-CCP antibody positivity in children with type 1 DM.

The reported frequency of anti-CCP positivity among healthy adults ranges from 0.4 to $2.6 \%^{7.10-12}$. In a recent study, Nisihara et al. ${ }^{13}$ investigated the prevalence of anti-CCP antibodies among Down syndrome patients 
because of the known association of this syndrome with an increased frequency of autoimmune diseases such as type 1 DM. A high prevalence, $52.3 \%$, was observed in this population and was attributed to the presence of anti-CCP as an early marker of rheumatic disease or as part of the spectrum of immune abnormalities observed in patients with this syndrome. Besides, authors of a cohort study including 1453 patients with Down syndrome reported no association between the syndrome and RA, although several patients with inflammatory joint disease were described ${ }^{14}$.

Few data exist regarding prevalence of antiCCP antibodies in children with type $1 \mathrm{DM}$ and, consequently, it is not clear if anti-CCP positivity would be an important finding or not in such patients. So, we aimed to determine the frequency of anti-CCP antibodies among a cohort of children with type $1 \mathrm{DM}$.

\section{Material and Methods}

This study was performed between December 2013 and March 2014. Diagnoses of type 1 DM were made according to the International Diabetes Federation criteria ${ }^{15}$. Patients with type $1 \mathrm{DM}$ and known positivity for at least 1 pancreatic islet autoantibody (e.g., anti-glutamic acid decarboxylase [anti-GAD] antibodies, islet cell antibodies [ICA], and anti-insulin antibodies) at the time of diagnosis were included in Group 1. The control group (Group 2) comprised of subjects without any chronic or autoimmune disease, who were evaluated for acute problems or routine control in the outpatient clinics.

The subjects were assessed for history of a chronic non-diabetic disease, joint involvement, or a familial history of RA. Individuals in both groups underwent a thorough physical examination prior to the study, and none of them exhibited any joint complaints or arthritis. During the day of the data collection, venous blood sample of $5 \mathrm{ml}$ was drawn from left antecubital vein of each subject, centrifuged at $1600 \times \mathrm{g}$ for 15 minutes, and separated serum samples were stored at $-20^{\circ} \mathrm{C}$ until the analysis was performed.

In the diabetes group, the serum levels of anti-thyroglobulin (anti-TgAb; reference range, 0-20 IU/ml) and anti-thyroid peroxidase (anti-
tPOAb; reference range, $0-34 \mathrm{IU} / \mathrm{ml}$ ) antibodies and positivity for anti-gliadin immunoglobulin (Ig) A, anti-gliadin IgG, and anti-endomysial antibodies during the previous 1-year period were recorded from the medical records. For each patient, the mean $\mathrm{HbAlc}$ levels were calculated using the results from the previous 1-year period.

Anti-CCP IgG antibody levels in sera were measured using a commercial solid phase, 2-cycle sequential chemiluminescent immunometric assay kit (IMMULITE 2000/ XPi; Siemens AG, Munich, Germany). According to the manufacturer's manual, clinical sensitivity was $78.2 \%$, and clinical specificity was $99.5 \%$. Within-run precision and coefficient of variation were $<11 \%$ and $<19 \%$, respectively. In accordance with the manufacturer's recommendations, cases with anti-CCP antibody levels $>4 \mathrm{U} / \mathrm{ml}$ were considered positive for anti-CCP. RF status was determined via turbidimetry (Aeroset and Architect; Abbott Diagnostics, Barcelona, Spain). Values $<30 \mathrm{IU} / \mathrm{mL}$ were considered negative.

After providing relevant information, written informed consent was obtained from the parents or legal guardians of all children participating in the study, and an extra volume of blood was drawn at the time of routine venipuncture. The study protocol was approved by the Ethics Committee of our institute and was performed in compliance with the World Medical Association Declaration of Helsinki.

\section{Statistical Analysis}

Statistical data analysis was performed using SPSS 17.0 software (SPSS, Inc., Chicago, IL, USA). Student's t test was used to compare continuous variables and data were presented as mean \pm standard deviation. When distribution of variables did not satisfy normal distribution assumptions, Mann-Whitney $U$ test was used and data were presented as median (minimum and maximum). The chi-square test or Fisher's exact test was used to compare categorical variables. A $p$ value $<0.05$ was considered significant.

\section{Results}

The study included 90 children with type 
1 DM (Group 1, male/female: 46/44; mean age: $10.5 \pm 3.9$ years) and 76 control cases (Group 2, male/female: 34/42; mean age: 9.8 \pm 3.7 years). The clinical and laboratory data are shown in Table I. The groups were similar with regard to age and gender. In group 1, the mean duration of type $1 \mathrm{DM}$ was $2.1 \pm$ 1.9 years, and the mean $\mathrm{HbAlc}$ value and mean insulin requirement were $9.65 \pm 1.98 \%$ (range: 6.12-15.75) and $0.85 \pm 0.28 \mathrm{IU} / \mathrm{kg} /$ day, respectively. The 2 groups did not differ in terms of family history of RA and RF positivity.

In group 1 , the positivity rates for at least 1 anti-thyroid and celiac autoantibody were $19.8 \%$ and $10 \%$, respectively while only 1 case $(1.1 \%)$ exhibited anti-CCP antibody positivity $(5 \mathrm{U} / \mathrm{ml}$, normal: $<4.00 \mathrm{U} / \mathrm{ml}$ ); whereas none of the controls were positive $(p$ $=0.999$ ). The single positive case in group 1 was a 9.5-year-old boy with no family history of RA and no relevant joint complaints or findings. He had been diagnosed with type 1
DM 2 months earlier and exhibited positivity for islet cell antibodies, anti-gliadin IgA, and anti-endomysial antibodies. However, his RF results and intestinal biopsy for celiac disease were negative.

\section{Discussion}

Concurrent autoimmune diseases, which have a substantial impact on public health, have become an area of research focus. However, data regarding the association between type 1 DM and RA are limited. A systematic review of 5 relevant studies reported the prevalence rate of type $1 \mathrm{DM}$ among RA cases to range from $0.32 \%$ to $5.95 \%{ }^{4}$. Among these studies, the only population-based study with an attentive methodology revealed a frequency of insulin-dependent DM among patients with RA of $0.6 \%$ (95\% confidence interval: $0.2-1.0 \%$ ), which did not exceed the prevalence of insulindependent DM among the general middle-aged population $(0.5-0.6 \%)^{16}$.

Table I. Clinical and Laboratory Characteristics of the Study Groups

\begin{tabular}{|c|c|c|c|}
\hline & $\begin{array}{l}\text { Group } 1 \\
(\mathrm{n}=90)\end{array}$ & $\begin{array}{l}\text { Group 2 } \\
(\mathrm{n}=76)\end{array}$ & $p$ value \\
\hline Age (years) & $10.5 \pm 3.9$ & $9.8 \pm 3.7$ & 0.196 \\
\hline Sex ratio $(M / F)$ & $46 / 44$ & $34 / 42$ & 0.413 \\
\hline Weight (SDS) & $0.50(-2.26-+2.87)$ & $0.19(-1.99-+2.23)$ & 0.064 \\
\hline Height (SDS) & $0.17(-2.42-+2.76)$ & $-0.17(-1.79-+2.49)$ & 0.008 \\
\hline BMI (SDS) & $0.52(-2.65-+2.45)$ & $0.41(-2.21-+2.33)$ & 0.707 \\
\hline Family history of RA & $3(3.3 \%)$ & $1(1.3 \%)$ & 0.626 \\
\hline Pubertal cases & $48(53.3 \%)$ & $39(51.3 \%)$ & 0.795 \\
\hline \multicolumn{4}{|l|}{ Positivity rates } \\
\hline Anti-GAD antibody* & $54(69.2 \%)$ & - & $\mathrm{N} / \mathrm{A}$ \\
\hline $\mathrm{ICA}^{\#}$ & $45(60.0 \%)$ & - & $\mathrm{N} / \mathrm{A}$ \\
\hline Anti-insulin antibody & $26(32.5 \%)$ & - & $\mathrm{N} / \mathrm{A}$ \\
\hline Anti-TgAb ${ }^{€}$ & $12(14.0 \%)$ & - & N/A \\
\hline Anti-tPOAb ${ }^{\alpha}$ & $15(17.6 \%)$ & - & $\mathrm{N} / \mathrm{A}$ \\
\hline Anti-gliadin IgA & $6(6.7 \%)$ & - & $\mathrm{N} / \mathrm{A}$ \\
\hline Anti-gliadin IgG & $1(1.1 \%)$ & - & $\mathrm{N} / \mathrm{A}$ \\
\hline Anti-endomysial Ab & $6(6.7 \%)$ & - & $\mathrm{N} / \mathrm{A}$ \\
\hline $\mathrm{RF}$ & $0(0.0 \%)$ & $0(0.0 \%)$ & 0.999 \\
\hline Anti-CCP & $1(1.1 \%)$ & $0(0.0 \%)$ & 0.999 \\
\hline
\end{tabular}

Data are presented as mean \pm standard deviation, median (range) or $\mathrm{n}(\%) . \mathrm{M} / \mathrm{F}=$ male/female; SDS $=$ standard deviation score; $\mathrm{BMI}=$ body mass index; RA = rheumatoid arthritis; Anti-GAD = anti-glutamic acid decarboxylase; ICA = islet cell antibody; Anti-TgAb = anti-thyroglobulin antibody; Anti-tPOAb = anti-thyroid peroxidase antibody; IgA = immunoglobulin A; IgG = immunoglobulin $\mathrm{G} ; \mathrm{Ab}=$ antibody; $\mathrm{RF}=$ rheumatoid factor; Anti-CCP $=$ anti-cyclic citrullinated peptide. $\mathrm{N} / \mathrm{A}=$ not applicable. ${ }^{*} \mathrm{n}=78,{ }^{*} \mathrm{n}=75,{ }^{\$} \mathrm{n}=80, \epsilon_{\mathrm{n}}=86,{ }^{\alpha} \mathrm{n}=85$. 
As anti-CCP antibodies have been presented as reliable and specific novel markers indicative of future RA development, they have generated particular interest in terms of predicting the appearance of disease in selected groups of patients with other autoimmune diseases. ${ }^{7}$ However, the association between adult type $1 \mathrm{DM}$ and RA remains controversial in the context of anti-CCP antibody positivity. A recent case-control study of adult patients (n $=1401$ ) provided evidence of a specific and significant trend toward an association between type $1 \mathrm{DM}$ and RA among anti-CCP positive patients $(\mathrm{n}=857,61 \%$, odds ratio: 7.3 [95\% CI: 2.7-20.0]) but not among anti-CCP negative patients $(\mathrm{n}=544,39 \%)^{8}$. However, DesplatJégo et al. ${ }^{9}$ reported the rarity of anti-CCP antibody positivity among adult patients with type $1 \mathrm{DM}$, even when DM was included in autoimmune polyendocrine syndrome type 2 , and suggested that the association between type $1 \mathrm{DM}$ and the immune processes leading to RA is very weak.

Our study results demonstrate that anti-CCP antibodies are rare in cases of type $1 \mathrm{DM}$ of short duration, with positivity rates that parallel the findings of frequency studies in healthy populations ${ }^{10}$. This result cannot be attributed to inappropriate patient enrollment, as the antithyroid and celiac autoantibody positivity rates were consistent with those reported previously ${ }^{2}$. The only patient in our study who exhibited anti-CCP antibody positivity had no clinical findings. Similarly, in the study by Nisihara et al. ${ }^{13}$, clinical evidence of RA or juvenile idiopathic arthritis was lacking, despite reported high rates of antibody positivity among children and adults with Down syndrome.

Anti-CCP antibodies have been reported to precede RA onset by several years, likely because of an initial trigger, and their presence appears to associate with the future development of RA (odds ratio: 15.9) ${ }^{17}$; however, the exact interval between the appearance of antibodies and the onset of disease is unknown. Therefore, anti-CCP antibody monitoring in pediatric patients at an increased risk for eventual RA development consequent to an autoimmune predisposition does not appear to be useful in the absence of arthritis. However, it is noteworthy that our patients were relatively younger (mean age: $10.5 \pm 3.9$ years), and therefore anti-CCP antibody and RF positivity and eventually clinical RA might still occur in the future.

The current study has several limitations. First, the study sample size was relatively small and involved a single center, which limits the generalizability of the study results. Second, the sample was drawn from a heterogeneous population with respect to age and diabetes duration. In addition, some recent studies have shown reactivity of anti-CCP antibodies against Epstein-Barr viral citrullinated proteins, which raises the question of the role of viruses in the induction of these autoantibodies ${ }^{18,19}$. However, we did not investigate this infection in our patients.

In our study, anti-CCP positivity was detected in only 1 patient without any clinical sign suggestive of RA or a family history, initially or in the 2-year follow-up. This single case with a high anti-CCP level will be followed up for RA screening; however, this positive result might be nonspecific and transient. In conclusion, in light of the above-described information, anti-CCP antibody screening in the follow-up of pediatric patients with type $1 \mathrm{DM}$ does not appear to be rational in the absence of any signs or symptoms of arthritis. However, larger cohort studies that include long-term follow-up are needed to determine the prevalence of antibody positivity in childhood and its association with the occurrence of RA later in life.

\section{Acknowledgements}

We thank all of our patients and their families, investigators, and staff for their participation in this study, and Gazi Kimya Laboratuar Sistemleri Ith. Ihr. San. ve Tic. A.Ş. for providing the anti-CCP and RF kits as a gift.

\section{REFERENCES}

1. Atkinson MA, Maclaren NK. The pathogenesis of insulin-dependent diabetes mellitus. N Engl J Med 1994; 331: 1428-1436.

2. Karavanaki K, Kakleas K, Paschali E, et al. Screening for associated autoimmunity in children and adolescents with type 1 diabetes mellitus (T1DM). Horm Res 2009; 71: 201-206.

3. Agrawal S, Desai MP. Simultaneous occurrence of type I diabetes mellitus and juvenile rheumatoid arthritis. Indian Pediatr 2003; 40: 568-571. 
4. Somers EC, Thomas SL, Smeeth L, Hall AJ. Autoimmune diseases co-occurring within individuals and within families: a systematic review. Epidemiology 2006; 17: 202-217.

5. Criswell LA, Pfeiffer KA, Lum RF, et al. Analysis of families in the multiple autoimmune disease genetics consortium (MADGC) collection: the PTPN22 620W allele associates with multiple autoimmune phenotypes. Am J Hum Genet 2005; 76: 561-571.

6. Kallberg H, Padyukov L, Plenge RM, et al. Genegene and gene-environment interactions involving HLA-DRB1, PTPN22, and smoking in two subsets of rheumatoid arthritis. Am J Hum Genet 2007; 80: 867-875.

7. Avouac J, Gossec L, Dougados M. Diagnostic and predictive value of anti-cyclic citrullinated protein antibodies in rheumatoid arthritis: a systematic literature review. Ann Rheum Dis 2006; 65: 845-851.

8. Liao KP, Gunnarsson M, Kallberg H, et al. Specific association of type 1 diabetes mellitus with anti-cyclic citrullinated peptide-positive rheumatoid arthritis. Arthritis Rheum 2009; 60: 653-660.

9. Desplat-Jego S, Deharveng I, Baronne R, Valero R, Begu-Le Corroller A, Vialettes B. Antibodies to cyclic citrullinated peptides (anti-CCP) in Type 1 diabetes mellitus. Diabet Med 2010; 27: 725-727.

10. Tasliyurt T, Kisacik B, Kaya SU, et al. The frequency of antibodies against cyclic citrullinated peptides and rheumatoid factor in healthy population: a field study of rheumatoid arthritis from northern Turkey. Rheumatol Int 2013; 33: 939-942.

11. Li T, Bao J, Yin J, Xu HJ. [The specificity of anti-cyclic citrullinated peptide antibodies in the diagnosis of rheumatoid arthritis from a large cohort study in the Chinese]. Zhonghua Nei Ke Za Zhi 2011; 50: 99-101.
12. Goeldner I, Skare TL, de Messias Reason IT, Nisihara RM, Silva MB, Utiyama SR. Anti-cyclic citrullinated peptide antibodies and rheumatoid factor in rheumatoid arthritis patients and relatives from Brazil. Rheumatology (Oxford) 2010; 49: 1590-1593.

13. Nisihara RM, Skare TL, Silva MB, et al. High positivity of anti-CCP antibodies in patients with Down syndrome. Clin Rheumatol 2007; 26: 2031-2035.

14. Goldacre MJ, Wotton CJ, Seagroatt V, Yeates D. Cancers and immune related diseases associated with Down's syndrome: a record linkage study. Arch Dis Child 2004; 89: 1014-1017.

15. Craig ME, Jefferies C, Dabelea D, Balde N, Seth A, Donaghue KC. Definition, epidemiology, and classification of diabetes in children and adolescents. Pediatr Diabetes 2014; (15 Suppl)20: 4-17.

16. Hakala M, Ilonen J, Reijonen H, Knip M, Koivisto $\mathrm{O}$, Isomaki $\mathrm{H}$. No association between rheumatoid arthritis and insulin dependent diabetes mellitus: an epidemiologic and immunogenetic study. J Rheumatol 1992; 19: 856-858.

17. Berglin E, Padyukov L, Sundin U, et al. A combination of autoantibodies to cyclic citrullinated peptide (CCP) and HLA-DRB1 locus antigens is strongly associated with future onset of rheumatoid arthritis. Arthritis Res Ther 2004; 6: R303-R308.

18. Anzilotti C, Merlini G, Pratesi F, Tommasi C, Chimenti D, Migliorini P. Antibodies to viral citrullinated peptide in rheumatoid arthritis. J Rheumatol 2006; 33: 647651.

19. Pratesi F, Tommasi C, Anzilotti C, Chimenti D, Migliorini P. Deiminated Epstein-Barr virus nuclear antigen 1 is a target of anti-citrullinated protein antibodies in rheumatoid arthritis. Arthritis Rheum 2006; 54: 733-741. 